\title{
INTERCRESCIMENTO GRÁFICO ILMENITA-CLINOPIROXÊNIO EM NÓDULOS DE KIMBERLITO DE JUÍNA, MT: PETROGRAFIA E QUÍMICA MINERAL
}

\author{
VICENTE SÉRGIO COSTA \& JOSÉ CARLOS GASPAR ${ }^{1}$
}

\begin{abstract}
RESUMO Foi encontrado um nódulo com intercrescimento gráfico ilmenita - clinopiroxênio em testemunho de sondagem de um pipe de kimberlito da província diamantífera de Juína (MT). O xenólito tem forma discóide, com aproximadamente $2,0 \times 1,5 \mathrm{~cm}$. A textura é gráfica com cerca de $20 \%$ de ilmenita em lamelas de $1 \mathrm{~mm}$ de espessura. Pelo geotermômetro que utiliza o coeficiente de distribuição Fe--Mg pode-se inferir que esse nódulo foi formado em temperatura elevada $\left(1264-1308^{\circ} \mathrm{C}\right)$ para uma pressão estimada de $45 \mathrm{kbar}$. A textura de deformação e a composição química dos minerais são semelhantes à suite de megacristais da província, indicando que o intercrescimento originou-se por cristalização cognata ilmenita-clinopiroxênio, o qual foi posteriormente deformado, resultando em neoblastos rotacionados de clinopiroxênio. Outros modelos genéticos não podem, no entanto, ser desconsiderados.
\end{abstract}

Palavras-chave: intercrescimento clinopiroxênio-ilmenita, xenólito, kimberlito, Juína

\begin{abstract}
GRAPHIC NTERGROWTH OF ILMENITE-CLINOPYROXENE IN KIMBERLITE NODULES FROM JUÍNA, MT: PETROGRAPHY AND MINERAL CHEMISTRY A xenolith composed of ilmenite and clinopyroxene intergrowth was found in the drill cores from one of the kimberlite pipes of the Juina Province, Mato Grosso. The xenolith has a disc shape, measuring about $2.0 \times 1.5 \mathrm{~cm}$. The texture is graphic with approximately $20 \%$ ilmenite, which occurs as lamellae of approximately $1 \mathrm{~mm}$ wide. The deformation texture and mineral chemical composition are similar to the megacrystal suite found in the same intrusion. In detail, the clinopyroxene is texturally complex, containing rotated sub-grains and clinopyroxene lamellae. Geothermometric measurement using the $\mathrm{Fe}^{2+}-\mathrm{Mg}$ partition coefficient yielded a temperature of $1264-1308^{\circ} \mathrm{C}$ for an estimated pressure of $45 \mathrm{kbar}$. The genetic model of ilmenite and clinopyroxenite coprecipitation may be invoked in this case, with later deformation processes. Other genetic models, however, cannot be ruled out.
\end{abstract}

Keywords: clinopyroxene-ilmenite intergrowth, xenolith, kimberlite, Juína

INTRODUÇÃO Nódulos de granulometria grossa contendo intercrescimento de ilmenita e piroxênio, encontrados principalmente em kimberlitos, têm recebido grande atenção na literatura por representar amostras cristalizadas a grandes profundidades no manto e possivelmente revelar indícios sobre as condições físico-químicas de formação dos kimberlitos.

Embora muitas outras ocorrências de intercrescimentos entre piroxênio e óxidos sejam descritas em cumulados profundos, como rochas gabróicas acamadadas, eles diferem dos encontrados em nódulos de kimberlitos em textura, escala, e composição química dos óxidos (Garrison \& Taylor 1981). Os nódulos contendo intercrescimento gráfico encontrados em kimberlitos ocorrem como um único megacristal $(1-2 \mathrm{~cm})$ de clinopiroxênio (ex.: Gurney et al. 1973) ou ortopiroxênio (ex.: Frick 1973) com lamelas (100-500 mm de espessura) paralelas de ilmenita magnesiana. Esse tipo de intercrescimento está amplamente documentado para os kimberlitos da África do Sul, Rússia e E.U.A (Dawson \& Reid 1970, Frick 1973, Boyd \& Nixon 1973, Gurney et al. 1973, Ilupin et al. 1973, McCallister et al. 1875, Smith et al. 1976, Eggler et al. 1979, Haggerty et al. 1979).

KIMBERLITOS DE JUÍNA A província kimberlítica/ diamantífera de Juína (PKDJ; ou Aripuanã, Schultz Filho 1981) localiza-se na parte meridional do Craton Amazônico. A grande maioria das intrusões kimberlíticas está instalada $\mathrm{cm}$ rochas sedimentares Permo-Carboníferas da Formação Fazenda da Casa Branca (Bacia dos Parecis; Siqueira 1989), porém, alguns corpos intrudem granito-gnáisses do embasamento regional (Fig. 1). Esse embasamento está representado, na área, por rochas da Província Rio Negro-Juruena (Cordani et al. 1979, Teixeira et al. 1989, Tassinari et al. 1996, Tassinari \& Macambira 1999).

Ocorrem cerca de 23 diatremas na província kimberlítica de Juína, que configuram amplas crateras circulares, com até 55 ha., compostas principalmente por piroclásticas subaéreas, tefras hidroclásticas e depósitos vulcaniclásticos (Teixeira et al. 1998a, b).

Estudos isotópicos de U-Pb em zircões mantélicos (Heaman et al. 1998) recuperados em kimberlitos de Juína e de Paranatinga indicaram dois períodos distintos para a formação desses zircões: um Cenomaniano (91,6 - 94,6 Ma. para Juína) e outro Barremiano (122,6 - 126,3 Ma. para Paranatinga).

XENÓLITOS MANTÉLICOS Os principais xenólitos mantélicos encontrados foram, por ordem de abundância, granada peridotitos, granada \pm espinélio peridotitos, eclogitos biminerálicos e coesita-sanidina eclogitos (Costa \& Gaspar e Costa et al., em preparação). Ocorrem ainda grandes quantidades de megacristais de granada, ilmenita, clinopiroxênio, flogopita e espinélio, além de raros nódulos ricos em mica e anfibólio e nódulo biminerálico com intercrescimento gráfico ilmenita - clinopiroxênio.

MÉTODOS ANALÍTICOS As análises químicas quantitativas para elementos maiores foram realizadas em 


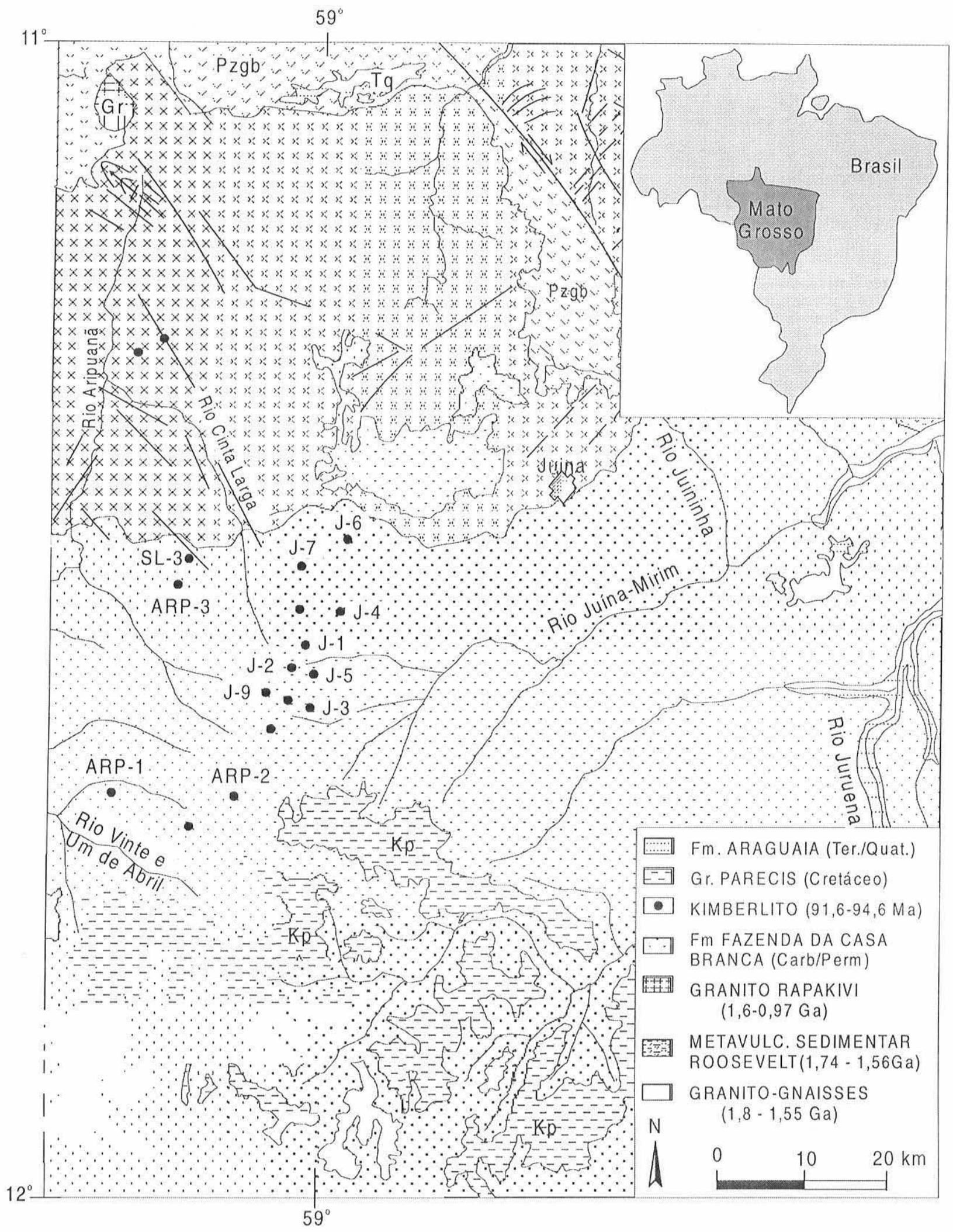

Figura I - Mapa geológico da provínciaddiamantífera de Juína, MT (modificado de Padilha et al. 1974) localizando as principais intrusões kimberlíticas. 
microssonda eletrônica (Cameca SX-50) no laboratório do Instituto de Geociências da Universidade de Brasília. As condições de operação foram $25 \mathrm{nA}$ e $15 \mathrm{kV}$ e com tempo de leitura de $10 \mathrm{~s}$ para cada elemento. A abertura do feixe utilizado foi de $5 \mathrm{~mm}$. Os fatores de correção são do programa PAP, com nível de precisão estatística de aproximadamente $0,1 \%$ para elementos maiores.

PETROGRAFIA Devido ao estágio avançado de alteração dos kimberlitos, foi recuperado somente um nódulo resistente para ser laminado, embora tenham sidos identificados outros poucos. O nódulo apresenta formato elipsóide com bordas arredondadas, dimensões que variam entre $2,0 \times 1,5 \mathrm{~cm}$ e com lamelas $(\sim 1 \mathrm{~mm})$ de ilmenita orientadas ao longo do eixo maior (Fig. 2a). A análise visual sugere que a proporção aproximada entre as fases é de $80 \%$ de clinopiroxênio e $20 \%$ de ilmenita.

Ao microscópio, o nódulo consiste de um único megacristal
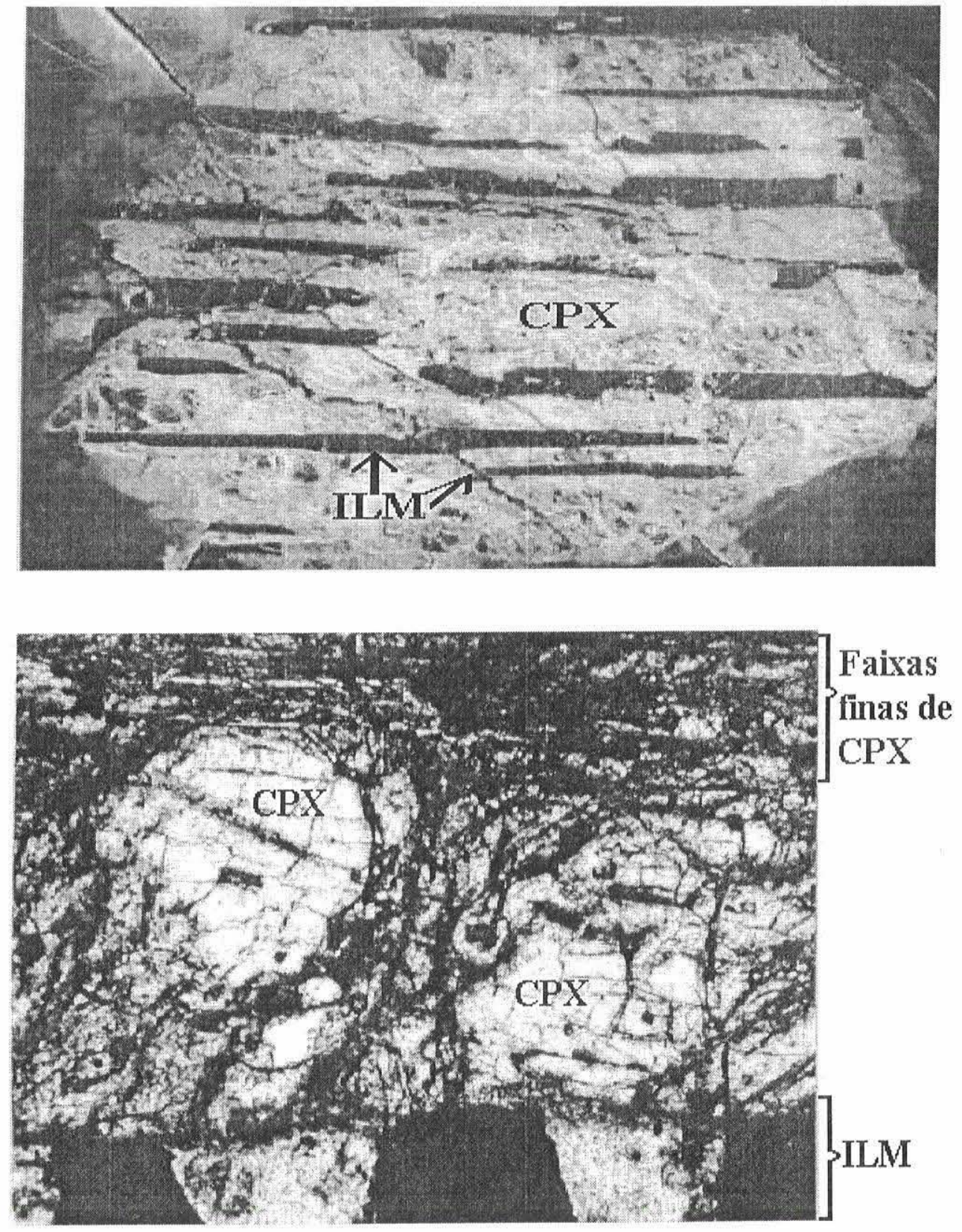

Figura 2 - A) Nódulo com intercrescimento gráfico de ilmenita (ILM) e clinopiroxênio (CPX) recuperado nos kimberlitos de Juína, MT, medindo $2 \times 1,5 \mathrm{~cm}$. B) Microfolografia mostrando detalhe da lamela de ilmenita ( I mm de espessura) (ILM; porção inferior), neoblastos recristalizados e rotacionados de clinopiroxênio (CPX) e faixa com CPX de granulação fina (porção superior). Campo total $=1,5 \mathrm{~mm}$ de largura. Luz transmitida, $\mathrm{N} / \mathrm{l}$. 
$(2 \mathrm{~cm})$ de clinopiroxênio cinza esverdeado, com lamelas de 0,5 a 1,0 mm de ilmenita orientadadas paralelamente. O cristal de clinopiroxênio apresenta fortes evidências de deformação, tais como extinção ondulante ao longo de toda sua extensão e a formação de sub-grãos (neoblatos) com dimensões entre 0,5 $2,0 \mathrm{~mm}$, resultando uma textura poligonal em mosaico de grãos recristalizados (Fig. 2b). Em alguns locais, ocorrem estreitas faixas de clinopiroxênio de granulação fina, orientados paralelamente à direção das lamelas (Fig. 2b).

Ao contrário do clinopiroxênio, nas lamelas de ilmenita não foram observadas texturas evidentes de deformação. Entretanto, ocorrem algumas raras agulhas orientadas, possivelmente de rutilo.

QUÍMICA MINERAL Análises químicas representativas de ilmenita e clinopiroxênio encontram-se na Tabela 1 . O cristal de clinopiroxênio apresenta composição química homogênea com conteúdo entre 40,32 e 41,68\% do componente wollastonita, entre 51,43 e $53,59 \%$ de enstatita e entre 4,74 e $7,59 \%$ de ferrossilita. O conteúdo de $\mathrm{Cr}_{2} \mathrm{O}_{3}$ e $\mathrm{Na}_{2} \mathrm{O}$ é baixo em relação à composição de clinopiroxênio de rochas mantélicas e varia entre 0,16 e 0,36 e entre 0,95 e $1,08 \%$ em peso, respectivamente. Também os conteúdos de titânio e alumínio mostram-se relativamente baixos, variando entre 0,32 e $0,42 \% \mathrm{em}$ peso de $\mathrm{TiO}_{2}$ e entre 1,61 e $1,75 \%$ em peso de $\mathrm{Al}_{2} \mathrm{O}_{3}$.

A composição química das lamelas de ilmenita mostra padrão homogêneo com conteúdo do componente ilmenita variando entre 46,60 e 51,43\% em peso, entre 39,32 e $41,55 \% \mathrm{~cm}$ peso geikielita e entre 8,58 e $11,85 \%$ em peso de hematita. Os conteúdos de $\mathrm{Cr}_{2} \mathrm{O}_{3}$ e $\mathrm{Al}_{2} \mathrm{O}_{3}$ está entre 0,88 e 1,19 e entre 0,51 e $0,92 \%$ em peso, respectivamente.

A Tabela 1 contém também dados químicos de megacristais de clinopiroxênio e de ilmenita que ocorrem na mesma província, A composição química do clinopiroxênio que compõe o nódulo de intercrescimento gráfico com ilmenita assemelha-se muito à composição química de megacristais de clinopiroxênio (baixo cromo) encontrados nos kimberlitos de Juína (Tabela 1 e Costa et al., 1997). Entretanto, na ilmenita ocorre uma diferença significativa quanto ao conteúdo de $\mathrm{Cr}_{2} \mathrm{O}_{3}$. Macrocristais de ilmenita apresentam conteúdo mais baixo de $\mathrm{Cr}_{2} \mathrm{O}_{3}(0,17-$ $0,19 \%$ em peso) que as lamelas de intercrescimento gráfico $(0,88-1,19 \%$ em peso).

As tentativas de análises químicas, por microssonda eletrônica, das faixas de clinopiroxênio de granulação mais fina, resultaram em composições com excesso de Ti. Este fato sugere a existência nessas faixas de cristais de ilmenita cuja granulação muito fina, não permitiu uma identificação ótica.

GEOTERMOMETRIA Admitindo-se que o sistema ilmenita-clinopiroxênio permaneceu fechado desde a sua formação, pode-se calcular a temperatura usando o geotermômetro da distribuição de $\mathrm{Fe}^{2+}-\mathrm{Mg}$ de Bihop (1980), que fornece um intervalo de temperatura entre $1405-1438^{\circ} \mathrm{C}$, para uma pressão estimada de 45 kbar.

Entretanto, usando-se a equação "13" de Bishop (1980) e corrigindo-se os coeficientes de distribuição de acordo com sugestão de Garrison \& Taylor (1981) obtêm-se um intervalo de temperatura mais baixa, entre $1264-1308^{\circ} \mathrm{C}$, a uma pressão estimada de $45 \mathrm{kbar}$, para a formação do intercrescimento gráfico de ilmenita-clinopiroxênio.
DISCUSSÃO A assembléia de megacristais de kimberlitos é tida como formada a uma profundidade média de $150-200$ km (temperatura entre $1190-1442^{\circ} \mathrm{C}$ e pressão de $52 \pm 1 \mathrm{kbar}$, Hops et al. 1992) ou logo abaixo do limite litosfera-astenosfera. Entretanto, não há consenso quanto à identificação do magma do qual derivaram os megacristais: i) se este magma é kimberlítico (proto-kimberlítico e/ou fenocristais de alta pressão em crystal-mush), os megacristais são considerados cognatos (Hunter \& Taylor 1984, Mitchell 1986, Canil \& Scarfe 1990), formados em um reservatório EM2 e origem profunda, possivelmente com contribuição de reciclagem de crosta oceânica (Nowell \& Pearson 1998), ou ii) se este magma é basáltico (reservatório de OIB e/ou HIMU) eles são considerados como xenocristais, sem nenhuma relação com o kimberlito hospedeiro (Jones 1987, Davies et al. 1991, Hops et al. 1992, Schulze et al. 1998, Bell \& Mofokeng 1998).

Embora muitos mecanismos para explicar a formação dos intercrescimentos gráficos de ilmenita-piroxênio tenham sido propostos, a sua origem ainda permanece incerta. Entre as principais alternativas estão: i) transformação eutética de granada (Ringwwod \& Lovering 1970); ii) exsolução a partir de um piroxênio com "estrutura de ilmenita" (Dawson \& Reid 1970); iii) substituição do piroxênio pela ilmenita (Frick 1973); iv) cristalização eutética (Gurney et al. 1973, Boyd \& Nixon 1973, Wyatt 1977); v) precipitação cotética (Frick 1973).

Gurney et al. (1973), listam alguns problemas sérios nos modelos de Ringwwod \& Lovering (1970) e Dawson \& Reid (1970), entre os quais a dificuldade de explicar a alta quantidade modal de ilmenita nos nódulos, visto que a solubilidade de $\mathrm{TiO}_{2}$ em piroxênio e granada, em pressão elevada, é bastante reduzida (Akela \& Boyd 1973). No entanto, granada ou piroxênio com alto Ti têm sido encontrados em kimberlitos ou como inclusão em diamantes (Meyer \& Boyd 1972).

Essas texturas de intercrescimento gráfico também não são bem explicadas em termos de exsolução (Garrison \& Taylor 1980), pois neste processo existe uma pequena força de direção para exsolver alguma fase em forma de agulha ou lamela. Por exemplo, seria difícil para um piroxênio exsolver uma fase rica em Mg (ilmenita magnesiana) a uma temperatura baixa e ainda reter um conteúdo molar de diopsídio sugestivo de equilíbrio em temperatura elevada.

Boyd (1971) argumenta que as texturas desses intercrescimentos são similares às texturas eutéticas produzidas por crescimento controlado em ligas. Wyatt (1977), em experimento bem sucedido, produziu crescimento eutético de ilmenita e clinopiroxênio com textura, composição e cristalografia semelhantes aos intercrescimentos encontrados em nódulos em kimberlitos.

Frick (1973) concluiu que a precipitação cotética é o modelo que melhor explica os intercrescimentos, devido à dificuldade de se explicar intercrescimentos tanto de ilmenita-clinopiroxênio quanto de ilmenita-ortopiroxênio por cristalização eutética.

Segundo Garrison \& Taylor (1981), dados experimentais e químicos favorecem a origem por co-precipitação para os nódulos com intercrescimentos gráficos encontrados em kimberlitos. A variação na textura (lamelar ou gráfica) pode estar relacionada tanto à taxa de resfriamento quanto ao modo de crescimento (ex.: lamelas planas).

O nódulo descrito neste trabalho apresenta composição se- 
Tabela I - Composição química média para ilmenita (ILM) e clinopiroxênio (CPX) em nódulo de intercrescimento gráfico e en megacristais

\begin{tabular}{|c|c|c|c|c|c|c|}
\hline $\begin{array}{c}\text { Mineral/ } \\
\text { Óxidos }\end{array}$ & Cpx & $\begin{array}{c}\text { Cpx } \\
\text { Megacristal }\end{array}$ & $\begin{array}{l}\text { Mineral/ } \\
\text { Óxidos }\end{array}$ & Ilm1 & $\operatorname{Ilm} 2$ & Ilm Megacristal \\
\hline $\begin{array}{l}\mathrm{n} .^{\circ} \mathrm{de} \\
\text { análises }\end{array}$ & (20) & (1) & & (36) & (31) & (3) \\
\hline $\mathrm{SiO}_{2}$ & 55,08 & 54,75 & & & & \\
\hline $\mathrm{TiO}_{2}$ & 0,38 & 0,34 & $\mathrm{SiO}_{2}$ & 0,05 & 0,07 & 0,01 \\
\hline $\mathrm{Al}_{2} \mathrm{O}_{3}$ & 1,68 & 1,62 & $\mathrm{TiO}_{2}$ & 52,38 & 52,39 & 51,76 \\
\hline $\mathrm{Cr}_{2} \mathrm{O}_{3}$ & 0,24 & 0,14 & $\mathrm{Al}_{2} \mathrm{O}_{3}$ & 0,72 & 0,74 & 0,60 \\
\hline $\mathrm{Fe}_{2} \mathrm{O}_{3}$ & 0,13 & 0,00 & $\mathrm{Cr}_{2} \mathrm{O}_{3}$ & 1,04 & 1,02 & 0,18 \\
\hline $\mathrm{MgO}$ & 18,01 & 17,63 & $\mathrm{Fe}_{2} \mathrm{O}_{3}$ & 6,28 & 6,31 & 7,21 \\
\hline $\mathrm{CaO}$ & 19,52 & 19,29 & $\mathrm{MgO}$ & 12,05 & 12,03 & 10,84 \\
\hline $\mathrm{MnO}$ & 0,08 & 0,09 & $\mathrm{MnO}$ & 0,20 & 0,19 & 0,22 \\
\hline $\mathrm{FeO}$ & 4,26 & 4,01 & $\mathrm{FeO}$ & 26,41 & 26,48 & 27,51 \\
\hline $\mathrm{NiO}$ & 0,02 & 0,19 & $\mathrm{NiO}$ & 0,13 & 0,12 & 0,06 \\
\hline $\mathrm{Na}_{2} \mathrm{O}$ & 1,00 & 0,96 & $\mathrm{ZnO}$ & 0,04 & 0,04 & 0,04 \\
\hline $\mathrm{K}_{2} \mathrm{O}$ & 0,03 & 0,04 & $\mathrm{Nb}_{2} \mathrm{O}_{5}$ & 0,10 & 0,09 & 0,00 \\
\hline Total & 100,43 & 99,06 & Total & 99,40 & 99,48 & 98,43 \\
\hline \multicolumn{7}{|c|}{ Cátions na base de 6 oxigênios } \\
\hline $\mathrm{Si}$ & 1,984 & 2,001 & & & & \\
\hline $\mathrm{Al}^{\mathrm{IV}}$ & 0,016 & 0,000 & & & & \\
\hline $\mathrm{Ti}$ & 0,010 & 0,009 & $\mathrm{Si}$ & 0,002 & 0,003 & 0,001 \\
\hline $\mathrm{Al}^{\mathrm{VI}}$ & 0,056 & 0,070 & $\mathrm{Ti}$ & 1,833 & 1,832 & 1,840 \\
\hline $\mathrm{Cr}$ & 0,007 & 0,004 & $\mathrm{Al}$ & 0,066 & 0,040 & 0,034 \\
\hline $\mathrm{Fe} 3+$ & 0,004 & 0,000 & $\mathrm{Cr}$ & 0,061 & 0,037 & 0,007 \\
\hline $\mathrm{Mg}$ & 0,967 & 0,960 & $\mathrm{Fe}^{3+}$ & 0,214 & 0,214 & 0,257 \\
\hline $\mathrm{Ca}$ & 0,753 & 0,755 & $\mathrm{Mg}$ & 0,813 & 0,834 & 0,764 \\
\hline $\mathrm{Mn}$ & 0,002 & 0,003 & $\mathrm{Mn}$ & 0,008 & 0,007 & 0,009 \\
\hline $\mathrm{Fe} 2+$ & 0,128 & 0,123 & $\mathrm{Fe}^{2+}$ & 1,000 & 1,030 & 1,087 \\
\hline $\mathrm{Ni}$ & 0,001 & 0,006 & $\mathrm{Ni}$ & 0,005 & 0,005 & 0,002 \\
\hline $\mathrm{Na}$ & 0,070 & 0,068 & $\mathrm{Zn}$ & 0,001 & 0,001 & 0,001 \\
\hline $\mathrm{K}$ & 0,001 & 0,002 & $\mathrm{Nb}$ & 0,002 & 0,002 & 0,003 \\
\hline Total & 3,999 & 4,001 & Total & 4,005 & 4,005 & 4,005 \\
\hline (\% Molar) & & & $\begin{array}{l}(\% \\
\text { Molar })\end{array}$ & & & \\
\hline Wo & 40,79 & 41,09 & Hem & 10,54 & 10,58 & 12,16 \\
\hline En & 52,37 & 52,24 & Geik & 40,12 & 40,00 & 36,24 \\
\hline Fs & 6,84 & 6,67 & $\mathrm{Ilm}$ & 49,35 & 49,41 & 51,61 \\
\hline
\end{tabular}

melhante a outros, recuperados em kimberlitos de várias regiões do mundo. O coeficiente de distribuição de $\mathrm{Fe}^{2+}$-Mg entre ilmenita e clinopiroxênio sugere que este nódulo foi formado em temperatura entre $1264-1308^{\circ} \mathrm{C}$, para uma pressão estimada de $45 \mathrm{kbar}$, consistente com temperaturas encontradas para nódulos semelhantes.

A composição química de ilmenita e clinopiroxênio de intercrescimento gráfico de Juína é semelhante à composição química de megacristais inclusos nos kimberlitos dessa região, apesar da diferença em cromo entre as ilmenitas do nódulo e megacristais. Este fato sugere uma ligação genética entre as duas suítes de minerais, mesmo considerando que os intercrescimentos são mais raros. Assim, o nódulo de Juína foi possivelmente formado por co-precipitação de ilmenita e piroxênio a partir de um magma (proto-kimberlítico?) em alta pressão, em condições semelhantes àquelas de formação dos megacristais.

Deformação posterior do nódulo originou e rotacionou neoblastos de clinopiroxênio e formou estreitas faixas de clinopiroxênio de granulação muito fina. Nessas faixas há evidências químicas (excesso de Ti nas análises do clinopiroxênio) da existência de cristais de ilmenita, que devem ser pouco abundantes e muito pequenos. As texturas observadas sugerem que o clinopiroxênio foi menos resistente à deformação que a ilmenita.

CONCLUSÕES Um nódulo com intercrescimento gráfico ilmenita-clinopiroxênio foi encontrado em kimberlitos da província diamantífera de Juína (MT), cuja temperatura de forma- 
ção é da ordem de 1264 a $1308^{\circ} \mathrm{C}$, para pressão estimada de $45 \mathrm{kbar}$, semelhante a nódulos encontrados em outras províncias. O nódulo de Juína formou-se por co-precipitação de ilmenita e piroxênio a partir de um magma em alta pressão. Deformação posterior do nódulo originou e rotacionou neoblastos de clinopiroxênio e formou estreitas faixas de clinopiroxênio de granulação fina.

Agradecimentos Agradecemos à Rio Tinto Desenvolvimento Mineral - RTDM pela doação das amostras, ao Conselho Nacional de Pesquisa-CNPq, ao laboratório de microssonda eletrônica d- Universidade de Brasília e aos revisores da RBG pelas sugestões ao manuscrito.

\section{Referências}

Akella J. \& Boyd F.R 1973. Effect of pressure on the composition of coexisting pyroxenes and garnet in the system $\mathrm{CaSiO}_{3}-\mathrm{MgSiO}_{3}-\mathrm{FeSiO}_{3}$. $\mathrm{CaAlTi}_{2} \mathrm{O}_{6}$. Carnegie Institution Washington Year Book, 72:523-526.

Bell D.R. \& Mofokeng H.J. 1998. Cr-poor megacrysts from the Frank Smith mine and the source regions of transitional kimberlites. In: $7^{\text {th }}$ Intern. Kimberlite Conf., Ext. Abs., pp.: 64-66.

Bbishop F.C. 1980. The distribuition of $\mathrm{Fe}^{2+}$ and $\mathrm{Mg}$ between coexisting ilmenite and pyroxene with applications to geothermometry. Am. Journal of Sci., 280:46-77.

Boyd F.R 1971. Enstatite-ilmenite and diopside-ilmenite intergrowths from the Monastery Mine. Carnegie Instituition Washington Year Book, 70:134 138.

Boyd F.R. \& Nixon P.H. 1973. Origin of the ilmenite-silicate nodules in kimberlites from Lesotho and South Africa. In: P.H. Nixon (Ed.) Lesotho Kimberlites, p. 254-268.

Canil D. \& Scarfe C.M. 1990. Phase relations in peridotitos $+\mathrm{CO}_{2}$ systems to 12 Gpa.: Implications for the origin of kimberlite and carbonate stability in the Earth's upper mantle. J. Geophys. Res., 95(B): 15,805-15,8I6.

Cordani U.G., Tassinari C.C.G., Teixeira W., Basei M.A S., Kawashita K. 1979. Evolução tectônica da Amazônia com base nos dados geocronológicos. In: Congr. Geólogico Chileno, 2, Actas, pp. 137-148.

Costa V.S., Figueiredo B.R., Weska R.K. 1997. Estudos mineralógicos e químicos do kimberlito Batovi 6 (MT) em comparação com as intrusões Três Ranchos 4 (GO) e Limeira I (MG). Geoch. Brasil., 11:53-71.

Costa V.S. \& Gaspar J.C. Garnet and spinel-garnet peridotite xenoliths from the Juína kimberlite, Brazil. Lithos (em preparação).

Costa V.S., Gaspar J.C., Pimentel M.M. Eclogite xenoliths from the Juína kimberlites, Brazil: 1,7 Ga. Subducted oceanic slab. (em preparação).

Davies G.R., Springs A.J., Nixon P.H., Rex D.C. 1991. A non-cognate origin for the Gibeon kimberlite megacryst suite. In.: $5^{\text {th }}$. Intern. Kimberlite Conf. Ext. Abs., 2/91: 63-65.

Dawson J.B. \& Reid A M. 1970. A pyroxene-ilmenite intergrowth from the Monastery mine, South Africa. Contrib. Mineral. Petrol., 26:296-301.

Eggler D.H., McCallum M.E., Smith C.B. 1979. Megacryst assemblages in kimberlite from nothern Colorado and southern Wyoming: petrology, geothermometry-barometry, and areal distribuition. In: F.R. Boyd \& H.O.A. Meyer (Eds.) The mantle sample: inclusion in kimberlites and other volcanics. V. 2, p. 213-226.

Frick C. 1973. Intergrowths of orthopyroxe and ilmenite from Frank Smith mine, near Rarkly West, South Africa. Trans. Geol. Soc. South Africa, 76:195200.

Garrison J.R. \& Taylor L.A. 1981. Petrogenesis of pyroxene-oxide intergrowths from kimberlite and cumulate rocks: co-precipitation or exsolution? Am. Mineral., 66:723-740.

Gurney J.J., Feso H.W., Klabe E.J. 1973. Clinopyroxene-ilmenite intergrowths from kimberlite: a re-appraisal. In: P.H. Nixon (Ed.) Lesotho Kimberlites, p. $238-253$.

Haggerty S.E., Hardie R.B. III, McMahon B.M. 1979. The mineral chemistry of ilmenite nodule associations from the Monastery diatreme, In: F.R. Boyd \& H.O.A. Meyer (Eds.) The mantle sample: inclusion in kimberlites and other volcanics, v.2, p. 249-256.

Heaman L., Teixeira N.A., Gobbo L., Gaspar J.C. 1998, U-Pb mantle zircon ages for kimberlites from the Juína and Paranatinga provinces, Brazil. Proceedings of the 7th International Kimberlite Conference, Cape Town. Ext. Abs., p.322-324.
Hops J.J., Gurney J.J., Harte B. 1992. The Jagersfontein Cr-poor megacryst suite - towards a model for megacryst petrogenesis. J. of Volcanol. and Geotherm. Research, 50:143-160.

Hunter R. H. \& Taylor L. A. 1984. Magma-mixing in the low velocity zone: kimberlitic megacrysts from Fayette Country, Pennsylvania. Am. Mineral., 69:16-29.

Ilupin I.P., Kaminskiy F.V., Troneva N.V. 1973. Pyroxene-ilmeinte graphic inclusions from the Mir kimberlite pipe (Yakutia) and their origin. Intern. Geol. Review, 16:1298-1305.

Jones R.A. 1987. Strontium and neodymium isotopic and rare earth elemem evidence for the genesis of megacrysts in kimberlites of Southern Africi. In: P.H. Nixon (Ed.). Mantle Xenoliths, p. 711-724.

McCallister R.H., Meyer H.O.A., Brookins D.G. 1975, "Pyroxene"-ilmenite xenoliths from the Stockdale pipe, Kansas: chemistry, crystallography and origin. Phys. Chem. Earth, 9:287-293.

Meyer H.O. \& Boyd F.R. 1972. Composition and origin of crystalline inclusions in natural diamonds. Geochim. Cosmochim. Acta, 36:1255-1273.

Michell R. H. 1986. Kimberlites: mineralogy, geochemistry, and petrology. Plenum Press, New York, 442p.

Novell G.M. \& Pearson D.G. 1998. Hf isotope constraints on the genesis of kimberlitic megacrysts: evidence for a deep mantle component in kimberlites. $7^{\text {th }}$. Intern. Kimberlite Conf. Ext. Abst., 634-636.

Ringwood A.E. \& Lovering J.F. 1970. Significance of pyroxene - ilmenite intergrowths among kimberlite xenoliths. Earth Planet. Sci. Lett., 19:371375 .

Schults Filho A V. 1981. Relatório de pesquisa MME/DNPM, 811.576/76; $811,579 / 76$ e $806.727 / 76$.

Schulze D.J., Valley J.W., Bell D.R., Spicuzza M. 1998. Significance of oxygen isotope variations in the $\mathrm{Cr}$-poor megacryst suite. In: $7^{\text {th }}$ Intern. Kimberlite Conf., Ext. Abs., p. 769-771.

Siqueira L. P. de 1989. Bacia dos Parecis. Boletim de Geociências da Petrobrás, $3(1 / 2): 3-16$

Smith C.B., McCallum M.E., Eggler D.H. 1976. Clinopyroxene-ilmenite intergrowths from the Iron Mountain kimberlite district, Wyoming. Carnegie Inst. Washington, Year Book, 75:542-544.

Tassinari C.C.G., Cordani U.G., Nutman A.P., van Schums W.R., Bettencourt J.S., Taylor P.N. 1996. Geochronological systematics on basement rocks from the Rio Negro - Juruena Province (Amazonian Craton) and tectonic implications. Intern. Geol. Review, 38:161-175.

Tassinari C.C.G. \& Macambira M.J.B. 1999. Geochronological provinces of the Amazonian Craton. Episodes, 22:174-182.

Teixeira W., Tassinari C.C.G., Cordani U.G., Kawsashita K. 1989. A review of the geochronology of the Amazonian Craton: tectonic implications. Prec. Res., 42:213-227,

Teixeira N.A, Gaspar J.C., Oliveira A.L.A.M., Bitencourt R.M., Yeda B. 1998a. Morphology of the Juína maars. In: $7^{\text {th }}$ Intern. Kimberlite Conf., Ext. Abs., p. $902-904$.

Teixeira N.A, Gaspar J.C., Waissel O, Almeira J.A, Gobbo L. 1998b. Geology of the Juina diamondiferous province. In: $7^{\text {th }}$ Intern. Kimberlite Conf., Ext. Abs., p. 905-907.

Wyatt B.A. 1977. The melting and crystallisation behabiour of a natural clinopyroxene - ilmenite intergrowth. Contrib. Mineral. Petrol., 61:1-9.

Manuscrito A-1308

Recebido em 26 de novembro de 2001 Revisão dos autores em 20 de dezembro de 200 Revisão aceita cm 21 de dezembro de 2001 